

\author{
International Journal of Heritage, Art and \\ Multimedia (IJHAM) \\ Journal Website: http://ijham.com/ \\ eISSN: 2600-8262
}

\title{
STUDY ON USAGE OF FABRIC REMNANTS ON YEMENI'S FASHION FOR WOMEN
}

\author{
Budoor Mohammed Thabit ${ }^{1}$, Hanisa Hassan ${ }^{2}$
}

1 Department of Fashion Design, Sana'a Community College (SCC), Yemen.

Faculty of Creative Technology and Heritage, Universiti Malaysia Kelantan (UMK), Malaysia

Email: budoor.alkubati@yahoo.com

2 Faculty of Creative Technology and Heritage, Universiti Malaysia Kelantan (UMK), Malaysia

Email: hanisa@umk.edu.my

\section{Article Info:}

\section{Article history:}

Received date: 21.08 .2019

Revised date: 02.02 .2020

Accepted date: 03.05.2020

Published date: 10.06.2020

\section{To cite this document:}

Thabit, B. M., \& Hassan, H. (2020). Study on Usage of Fabric Remnants on Yemeni's Fashion for Women. International Journal of Heritage, Art and Multimedia, 3 (9), 01-10.

DOI: $10.35631 /$ IJHAM.39001.

\begin{abstract}
:
The big quantity of fabric remnants was thrown away in Yemen due to a lack of knowledge and competency in reusing the remnants as material for making clothes. It has become a burden to the consumers and also bad for the environment. Therefore, this research aims to understand why the seamstress in Yemen wasted a lot of remnants and the possibility of using the remnants in making innovative designs on Yemenis traditional clothing such as Abaya and Galabiah. In order to answer the objectives, the researcher applies the qualitative approach in order to describe and understand the problems stated for this study by made several interviews with Yemeni's respondent who used to be a seamstress in Yemen, besides her personal experience when working in the workshop in Yemen. The prior objective is to recognise what was done to remnants in sewing workshops. Secondly, the researcher will be producing a design line using remnants with various techniques of embellishment to create new designs for Yemen's traditional costume of Abaya and Galabiah. The researcher hopes that through her innovation can inspire other designers or seamstress to use remnants as a source of material in making clothes. At the end of this study, the researcher found out that her Yemeni's respondents threw away remnants because they do not have the knowledge and skill to turn remnants into fashion. Plus, they are also lazy to think of recycling remnants since they had lots of orders from clients. In the end, the researcher made a questionnaire about the final designs and they did agree that remnants can be used to make beautiful traditional Yemeni's dress. Since remnants came from different sources, the design made is unique and one-off, which is the preference for most Yemenis. The researcher also proved that innovative and creative thinking are vital in creating designs, and hopefully it can change the perspective of Yemeni women towards the usage of remnants in fashion.
\end{abstract}

\section{Keywords:}

Fashion, Remnants, Yemen 


\section{Introduction}

Through observation in several sewing workshops and factories back in Yemen in 2013 to 2014, the researcher discovered that fabric remnants were wasted extensively and always being overlooked. Therefore, the researcher is highly interested in tackling the problem through innovative approach on garment making by using various techniques, such as patchwork and appliqué (Sikarskie, 2020; Sabbagh, 2011). These techniques may change the usage of remnants, so that it can be turned into creative artworks for fashion (Guilford, 1897). Expectantly via this study, new designs will be produced out of fabric remnants using various techniques in sewing (Sabbagh, 2007).

Based on the researcher's personal observation and experience when working in Yemen, was that dressmakers there wasted large quantity of fabric due to several factors. The most significant factor was, many designers in Yemen cannot determine the actual quantity needed to produce a tailored-made design. Most dressmakers in Yemen will ask the costumer to bring extra fabric from what was actually needed, which ended up as remnants. Secondly, Yemeni dressmakers have not been exposed to different techniques in dress making such as recycling remnants, resulting remnants are often thrown away after completion of certain garments (Jahaf, 2009). Dressmakers in Yemen do not bother of recycling the remnants that somehow contributes to the environmental problem. Secondly, most designers in Yemen were very busy with their orders and often do not have time to think of recycling remnants, especially during the seasons of wedding and Eid (Jahaf, 2013).

The prevailing method of making clothes involves cutting fabrics into different pieces and assembling the pieces through sewing. A large amount of fabric is often wasted in this process (Rissanen, 2013; Hamid, Skinder, \& Bhat, 2020). However, it should be noted that these processes are not only the main cause of wasting clothes and fabric remnants. Previous studies have shown that there are some other causes as mentioned by Laitala and Klepp (2011, p. 44) stating,

"Most of the wasted fabrics in clothing workshops can be attributed to several causes. One of the causes of wasted fabrics is the dress maker commitment to the need of the customer".

Taking this cause into account, the designer had to be stick to certain design where a large quantity of clothes is wasted in this way. The designers are sometimes obligated to current trends that are changing too fast nowadays, which involves different styles and materials, thus they threw away the past materials in order to keep up with the upcoming trends.

Rissanen (2013, p. 22) had recently claimed that most designers are not creative by profession, unprepared for any task but copying, and unaware of the possibilities of their profession. Furthermore, it has been argued by other researchers that there are practically no schools to provide designers with adequate training. This may lead to factors of inadequate number of trainers or teachers in fashion. Thus, designers depend mostly on what they call 'inspiration'; a good and wholesome word whereby common consent and abuse; designers are perverted into the contrary of its original meaning (Rissanen, 2013, p. 120).

Inspiration, from a designer's point of view, is far from the sublime moment of spiritual communion with divinity. In other words, the concept of inspiration to a designer simply means copying of unimportant and meaningless details from past epochs or foreign countries, which 
then attached securely together into that pastiche; this is referred to as The Style (Rudofsky, 1947, p. 223). Therefore, designers must produce items and products that match the needs of their customers.

In Arab countries, various researchers have pointed out that fabric is also wasted in large quantity (Atwah, 2012, p. 17). One of the early studies concerning this essential issue is Ibrahim and Mustafa (1996) who investigated the waste of fabric in Arab countries. They reported that fabrics are wasted in clothing industries because dressmakers ignored the actual quantity needed in each design that differs. They are obligated to the costumers' desires and designs which are following the trends.

Thirdly, the seamstress did not use the remnants to make Yemenis costumes may due to the lack of ideas and techniques to keep up with current fashion. The researcher suggested innovative and creative ideas in using remnants for traditional Yemeni's costume for women through experimental methods and various types of needle works.

The current study seeks to achieve the following objectives, i) to understand how fabric remnants are treated in garment workshops in Yemen, ii) to recognise what was done to remnants in sewing workshops and iii) to propose a design line for Yemeni's women using remnants with various techniques of embellishment to inspire designers. Therefore, the research questions are:

i. How did fabric remnants being treated in garment workshops in Yemen?

ii. What was done to remnants in Yemen sewing workshops by seamstresses?

iii. How can remnants be incorporated as material in fashion for Yemeni's women?

\section{Literature Review}

Wastage in terms of fabric remnants in Arab countries is a commonly led to extensive amount of clothes being thrown away. However, this issue had always being overlooked due to the lavish lifestyle among the Arabs. The Global Recycling Magazine (2016) had written a review regarding fabric waste in Arabic countries, mentioning that these countries are still in their early stage of using recycled materials. Mustafa (1995), Ibrahim and Mustafa (1996) also investigated the accumulation of fabrics remnants in the Arabs' factories which they found out that the huge wastage were the result of ignorance among its society when making or buying clothes. They usually disregarded the actual amount of fabric needed when making a garment by buying more material than what was actually needed because they can afford to pay.

There have been many studies conducted to investigate how to use fabric remnants in innovative designs, for example Anderson (2014) who had researched on how to reduce fabric remnants to benefit the economy in a society. Al-Sarhaan (2011) had demonstrated on how to use fabric remnants to make furniture accessories. As well as Atwah (2012) who had turned fabric remnants into fashionable dresses and bags. Ali and Mustafa, (2003) said that recycling of cloth wastes means, to reuse the small pieces of cloths or cloth wastes resulting from the stages of manufacturing the readymade clothes particularly in the cut stage of making a new product. Recycling is important to bring benefit and beautify a product. These small pieces of remnants are used mainly to produce new product in an innovative way (Ali \& Mustafa, 2003). Atwah, (2012) in her Master study demonstrated how it was being turned into innovative women's fashion. As stated by Modi (2015) and Rathinamoorthy (2018), fabric such as offcuts and end-of-rolls, that normally being thrown away, can always use to create the beautiful pants and scarves. 
Dressmakers can be found anywhere in the world, however not all dressmakers have adequate knowledge to make all sorts of designs without wasting fabric (Hamon, 2007). Anderson (2014) revealed that the selling price of fabric had fallen since 1995 however the demand for new clothes and styles are rapidly increasing. Thus, Anderson (2014) confirmed that this is the main cause that had pushed designers or dressmaker to use more fabrics because its cheap. Usage of fabric is exaggerated in order to achieve customer's satisfaction, neglecting the amount of fabric that will ended up as trash.

In Saudi Arabia, Makrash (2010) used different method to apply fabric remnants when designing a line. She was inspired by the geographical location of Saudi Arabia, she used her love for nature to make clothes with colours inspired from sand and sea. Atwah (2012) took advantages of fabric waste by distinguishing its potential in making innovative designs or other new products. So, Atwah collected fabric wastes to create innovative and integrated designs. In order to preserve the environment from pollution and congestion, she also contributes to fashion design practices and inspires women to create innovative designs.

\section{Methodology}

This study applies the qualitative approach in order to describe and understand the problems stated for this study. The qualitative method will help the researcher to understand why Yemeni dressmakers ignore the extensive wastage of fabric via interviews with four seamstresses where the researcher will interview them face-to-face to gather information. Data will be recorded using voice recorder. The voice recorded interviews will be translated into English. After that, the data will be transcribed into written documented data. This technique will be used to gather data to answer the first and the second research questions.

In order to answer the third research question, the researcher will then make the designing processes using experimental technique whereby experiments on fabric remnants will be recorded as data. The experiments will be made by testing a few techniques of needlework that can be best applied onto fashion that may be accepted by Yemeni's market. The organized experiment will be done systematically to ensure the results are adequate to answer the third research question regarding designing fashion for Yemeni's women. Analysis of data will be carried out to accept or reject the hypotheses as stated earlier, which are:

i) Remnants are ignored as wastage thus it is thrown away in most garment workshops in Yemen.

ii) Dressmakers in Yemen ignore the usage of remnants due to the financially stabled society.

iii) Remnants can be incorporated as a new style in fashion for Yemeni women if used innovatively and creatively.

Collection of data will be subjected to the research questions that will determine the source of data. The source of data is related to the types of instrument used to obtain the data. Overall, data collection can be summarized in Table 1: 
Table 1: Data Collection and Instrument

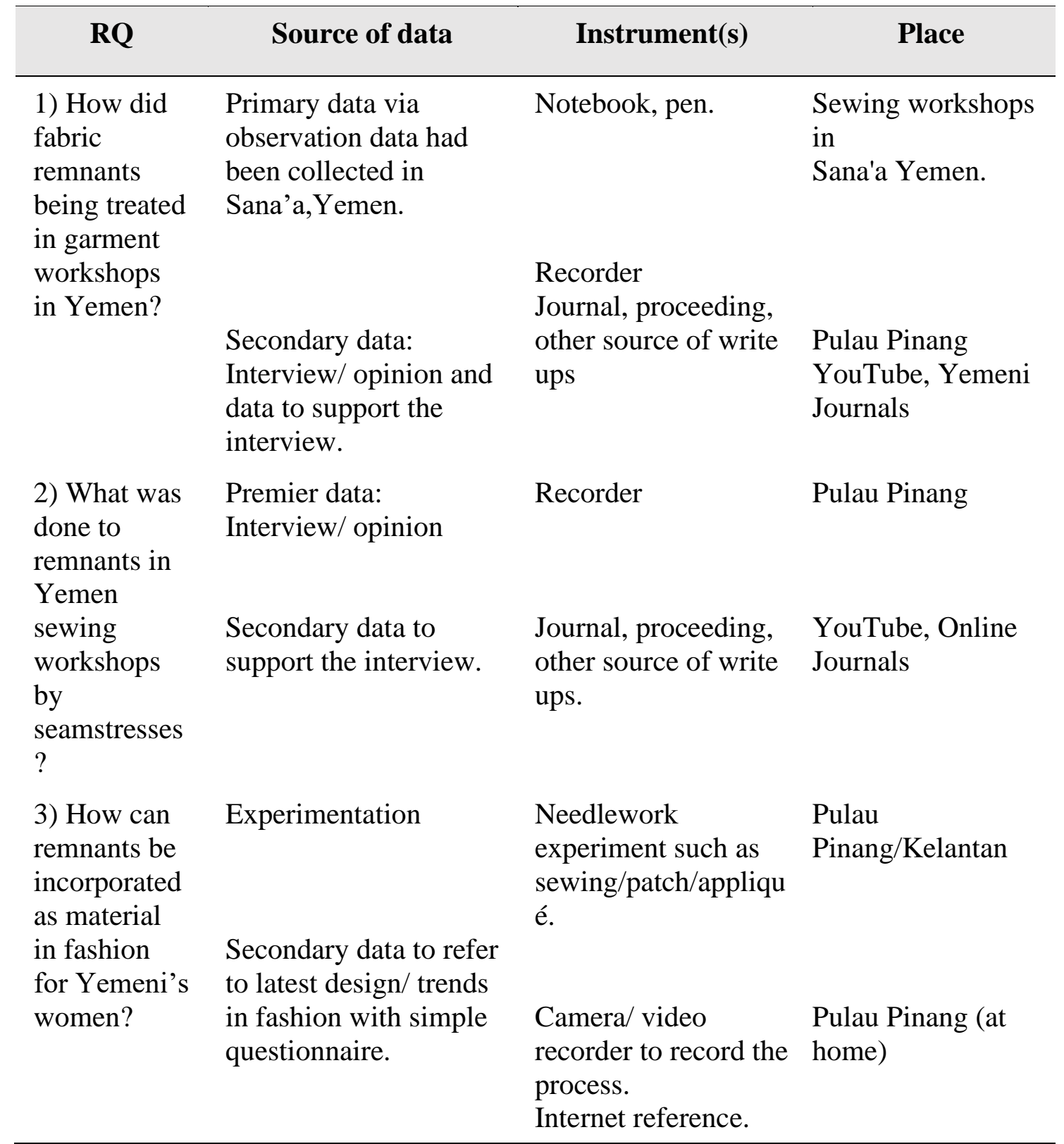

\section{Discussions}

The first hypothesis (which is: remnants were ignored as wastage thus it is not used as material or making clothes in Yemen). This may due to many reasons as per described in the interview data, documentation data and the observation data by the researcher. Data from the interview had been triangulated with the researcher's observational data which she obtained during her working experience in Yemen and documentation data. The interviews were held with the following respondents as in the Table 2 below: 
Table 2: Show Personal Data with Seamstress

\begin{tabular}{|c|c|c|}
\hline $\begin{array}{l}\text { Name of } \\
\text { respondent }\end{array}$ & Place of work in Penang & $\begin{array}{l}\text { Date and Time of the } \\
\text { interview }\end{array}$ \\
\hline 1) Aom & Third floor Bukit Jambul Pulau & $22^{\text {nd }}$ January 2018. 5:30 \\
\hline Waleed & Pinang & pm. \\
\hline 2) Sanaa Talb & $\begin{array}{l}\text { First floor Bukit Jambul Pulau } \\
\text { Pinang }\end{array}$ & $\begin{array}{l}24^{\text {th }} \text { January 2018. 6:15 } \\
\text { pm. }\end{array}$ \\
\hline $\begin{array}{l}\text { 3) Assmaa } \\
\text { Najeeb }\end{array}$ & In her home Pulau Pinang & $\begin{array}{l}14^{\text {th }} \text { February } 2018.6 \\
\text { pm. }\end{array}$ \\
\hline 4) Aumr & Butterworth workshop Pulau & $24^{\text {th }}$ February $2018.4: 40$ \\
\hline Ahmed & Pinang & pm. \\
\hline
\end{tabular}

The interviews had revealed that the garment workshops in Yemen had:

i) Large quantity of fabric remnants and accumulated weights between from 8 to $20 \mathrm{~kg}$ or more (per week or month) depending on the seasons.

ii) The length of fabric remnants ranged from $10 \mathrm{~cm}$ to $120 \mathrm{~cm}$ in various materials and textures.

iii) The fabric remnants will accumulate during school holiday, wedding and Eids celebration.

The researcher had conducted a field trip to garment workshops in the capital city of Sana'a in Yemen. She had collected the fabric remnants in bags and then weighted them. To facilitate this task, five different areas were selected in the capital city of Sana'a, which are i) Jamal Street, ii) Hayil Street, iii) Old Sana'a, iv) Alhusaba and v) Haddah Street. Each area consists several workshops and data were taken from two to four workshops in each location in a month during different seasons as mentioned in the interview. The data gathered were summarised as below:

Table 3 Show Fabrics Remnants in Garment Workshops at Sana'a Yemen in 2014

\begin{tabular}{|c|c|c|c|c|c|c|c|c|}
\hline Seasons & \multicolumn{2}{|c|}{$\begin{array}{l}\text { School } \\
\text { Season }\end{array}$} & \multicolumn{2}{|c|}{$\begin{array}{c}\text { Eids } \\
\text { Season } \\
\end{array}$} & \multicolumn{2}{|c|}{$\begin{array}{l}\text { Wedding } \\
\text { Season }\end{array}$} & \multicolumn{2}{|c|}{$\begin{array}{l}\text { Winter } \\
\text { season }\end{array}$} \\
\hline $\begin{array}{l}\text { Weight } \\
\text { The zone }\end{array}$ & $\begin{array}{l}\mathbf{K} \\
\mathbf{g}\end{array}$ & $\%$ & $\mathbf{K g}$ & $\%$ & Kg & $\%$ & Kg & $\%$ \\
\hline 1.Jamal Street & 20 & 26.3 & 50 & $\begin{array}{c}29 . \\
8\end{array}$ & 55 & $\begin{array}{c}24 . \\
4\end{array}$ & 25 & 31,3 \\
\hline 2.Hayil Street & 17 & 22.4 & 43 & $\begin{array}{c}25 . \\
6\end{array}$ & 47 & $\begin{array}{c}20, \\
9\end{array}$ & 17 & 21.2 \\
\hline 3. Old Sana'a & 15 & 19.7 & 27 & $\begin{array}{c}16 . \\
1\end{array}$ & 45 & 20 & 15 & 18.8 \\
\hline 4.Alhusaba & 13 & 17.1 & 26 & $\begin{array}{c}15 . \\
5\end{array}$ & 40 & $\begin{array}{c}17 . \\
8\end{array}$ & 13 & 16.2 \\
\hline $\begin{array}{l}\text { 5.Haddah } \\
\text { Street }\end{array}$ & 11 & 14.5 & 22 & 13 & 38 & $\begin{array}{c}16 . \\
9\end{array}$ & 10 & 12.5 \\
\hline Total & 76 & 100 & 168 & 100 & 225 & $\begin{array}{c}10 \\
0\end{array}$ & 80 & 100 \\
\hline
\end{tabular}


From the observation data, the fabric remnants accumulated during each season showed that the fabrics remnants can reached up to $76 \mathrm{~kg}$ during school holiday and up to $80 \mathrm{~kg}$ during winter. During the Eids (Al-Fitr Eid and Adha Eid) it can reach up to168 kg and $225 \mathrm{~kg}$ during wedding season. The data indicates that the quantity of fabric remnants was high during wedding seasons, followed by Eids, winter and school holiday, respectively.

Moreover, this had confirmed the relationship between observational data and the interview information. It reveals that there is a huge wastage in fabric, especially during the celebration of Eids and school holidays when weddings normally took place.

The second hypothesis stated that dressmakers in Yemen ignore the usage of fabric remnants due to many reasons. These reasons found from the interview data are as follow:

i) Lack of experience and creativity among the seamstress are the main reasons for not using fabric remnants as clothing materials.

ii) Most of the seamstresses were not formally trained in making clothes. They had picked the sewing career while working with their parents or friends. Therefore, they were not competent in making clothes.

iii) Most of the seamstresses only want to satisfy their customers by making whatever acquired by them. So, they do not have time to experiment on remnants.

iv) Most of the customers in Yemen contributed to the wastage because they do not opt to use similar material or designs with other customers even among their family members.

v) Most seamstresses also did not know how much fabric is needed in making certain designs.

The third hypothesis is to prove that remnants can also be used for making garment that can be accepted by Yemeni women. The designing and Experimentation Processes had been triangulated with simple questionnaire by Yemeni's respondents we asked whether the design can be acceptable or otherwise.

In order to see whether the designs are accepted by Yemenis women, a set of simple questionnaires was done using Google form/ paper, by displaying the finished garments. The Yemeni's respondents we asked whether the design can be acceptable or otherwise as shown in Figure 1. The designs which were made by the designers are shown to selected respondents, who are Yemeni women who resided in Malaysia. Four from them had worked in Yemen before as seamstress and six housewives. Therefore, their opinion on the collection made will determine whether the designs can be accepted or not by the Yemeni women. 


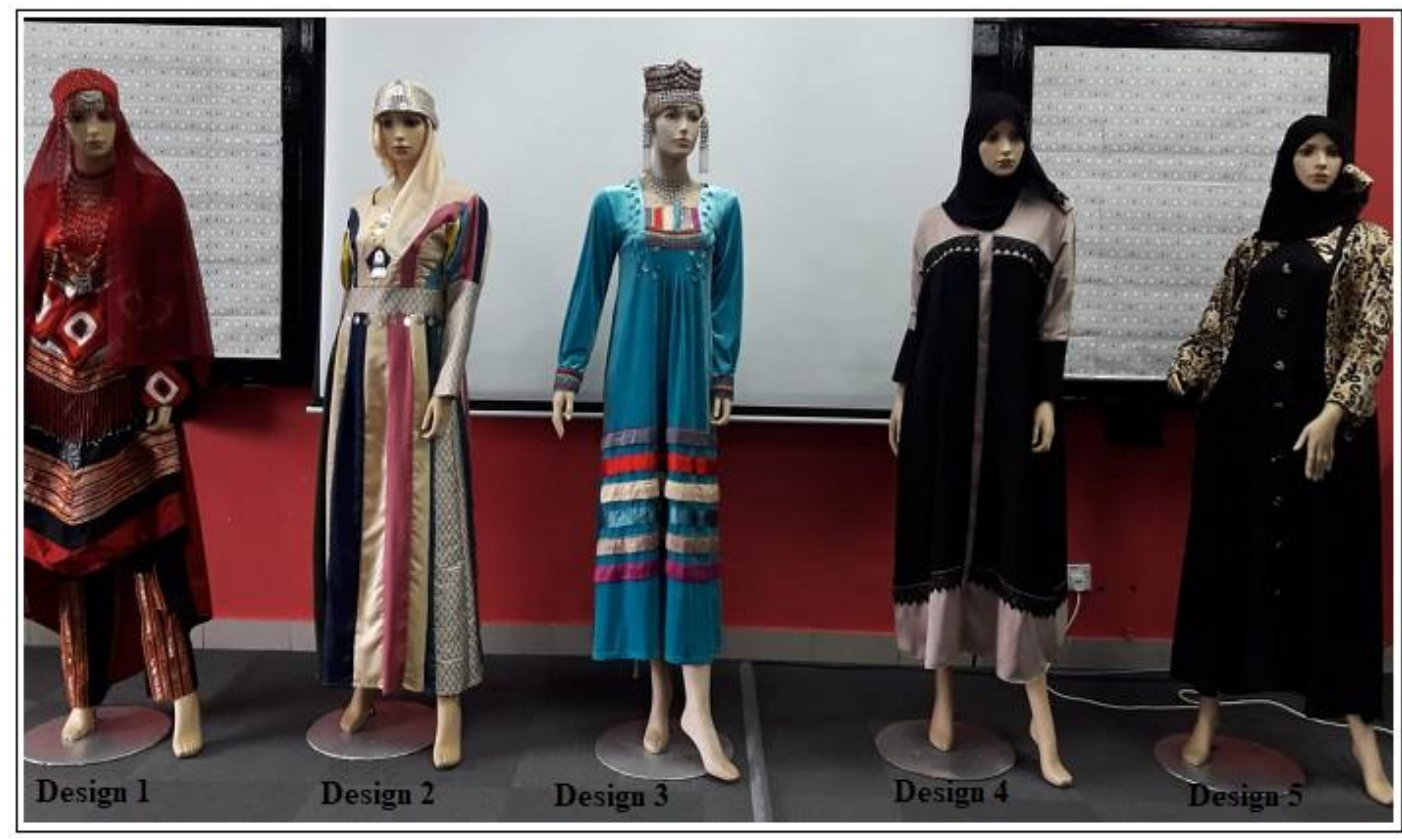

Figure 1: The Five Designs Made from Remnants

Through experiments on remnants (Abaya and Ghalabiah), it proved that fabric remnants can be used as material to make creative garments. It also confirms that due to the tedious processes during the making of garments from remnants, it suggested why dressmakers in Yemen ignored the usage of fabric remnants. The researcher also proved that innovative and creative ideas can change opinion and perspective of Yemeni' customers or seamstress in accepting remnants as material for making fashion. Since remnants are mixtures of various fabrics, the combination will never be similar to others, just like the preferences of the Yemeni.

\section{i) Finding 1}

Triangulation from the interview data, with the self-observation and report from journals, it can be concluded that fabric remnants were ignored in Yemen. Fabric remnants are never considered to be recycled in Yemen that proved the first hypothesis regarding fabric remnants gone to waste in Yemen. It also answered how fabric remnants were treated in Yemen, which is by throwing them away (refer to data in Table 3).

\section{ii) Finding 2}

Based on the prior findings, further discussion concludes that dressmakers in Yemen ignored the usage of fabric remnants due to a few common reasons. The reasons concluded were:

i. Lack of knowledge and time to experiment the usage of remnants as material in making garments.

ii. Customers bought extra fabric without proper guidance from the seamstress.

iii. Most seamstresses are not trained to deal with fabric remnants therefore they are not creative enough to turn them into garments.

\section{iii) Finding 3}

Through experiments, it shows that remnants can be turned into creative garments that may be accepted by Yemeni women. This was based on answers derived from questionnaires distributed among the Yemeni staying in Malaysia regarding the end product made from remnants. Even though the process of making the garments from remnants are rather tedious compared to the full length of fabric (since it does not involve patching of fabric) it supports 
recycling and hopefully helps reducing pollution. Therefore, it may be inferred that fabric remnants can be incorporated as material in fashion for Yemeni's women.

\section{Conclusion}

In line with the first objective that aimed to identify how fabric remnants were treated in seamstress workshops in Yemen. The first finding revealed that extensive amount of fabric remnants was wasted in garment workshops in Yemen. This scenario is bad or the environment since fabric remnants was not recycled in most garment workshops in Yemen. This had indicated that fabric remnants are completely ignored in Yemen. The finding confirms the first hypothesis which stated that 'remnants were ignored as wastage', since most fabric remnants were thrown away in Yemen. The first findings also proved the statement from first theory as mentioned in the literature. Research question number two is to try recognizing the reason why dressmakers in Yemen ignore the usage of remnants in women sewing workshops.

The study also revealed that dressmakers in Yemen ignored the usage of fabric remnants due to a few reasons. The first reason is the lack of experience and creativity among the seamstress. They are also lacking technical capability and idea on how cope with current fashions.

Secondly, customers always buy extra length of fabric without discussing it with the dressmaker. Thus, it led to wastage. Most dressmakers in Yemen request the customer to bring extra length of fabric because they cannot determine how much fabric is actually needed to make a garment.

The third reason is that most of the seamstresses in Yemen are ignorant due to lack of knowledge in construction a garment. Therefore, Yemeni's dressmakers have not been exposed to different techniques that can be used to recycle fabrics which led to large quantity of wastage. Dressmakers in Yemen also do not bother to recycle their remnants which again contribute to the environmental problem. Most designers in Yemen are busy coping with orders that they do not have time to experiment. This had confirmed the validity of the second hypothesis in which stated that 'dressmakers in Yemen ignored the usage of remnants' due to the reasons as stated above.

The last objective is to produce a design line by using fabric remnants to prove that remnants can be a source of material which is equally good in producing a fashion. The third finding confirms the statement as stated in the innovation theory as mentioned from Chap II. From the experiments done, it showed that fabric remnants can be incorporated to be a new style for Yemeni women when used innovatively and creatively. This experimental helps to protect the environment and contribute to raise economic awareness for dressmakers and promote scientific education.

The experiments were made from testing a few techniques of needlework embellishments which were combined with other techniques (such as patchwork and appliqué) to suit Yemeni women's preferences.

i. There is a tremendous amount of fabric remnants that were wasted in Yemen garment workshops.

ii. The dressmakers in Yemen ignored the usage of fabric remnants due to many reasons.

iii. Technical methods such as patchwork and the appliqué can be used to attach the remnants and turned into creative designs. 
iv. Fashion lines can be made possible using fabric remnants in the future and helps to protect the environment and contribute to raise economic awareness for dressmakers

\section{Recommendations}

i. Designers and dressmakers in the field of fashion design especially in Yemen should have creative and innovative idea by combining fabric remnants in their design line.

ii. Training and workshop should be done to expose Yemeni seamstresses on how to reduce fabric wastage. Remnants should be considered as a source of material in making garment.

iii. Making small projects from fabric remnants should start from school, so that awareness can be created in early age.

iv. More training on fashion should be provided to dressmakers in Yemen so that they will know how to estimate the correct length of fabric needed in order to make a garment. This can help to reduce wastage.

v. Garment factories or workshops in Yemen should make more garments using recycled materials in the future in order to reduce wastage and fight pollution.

vi. Conduct further studies on the possibility of benefiting from fabric remnants in the Yemeni society and identify the mechanisms and methods that can help to increase one's economy.

\section{References}

Ali, \& Hanan, S. M. (2003), Recruitment of Textile Exhausts in Ready Made Garments, Master Thesis, Ain Shams University, Cairo, Egypt.

Al-Sarhaan, T. M. (2011): Recycling of Textile Residues for Use in Furniture Accessories, Master Thesis, College of Arts and Design, King Abdul Aziz University, Jeddah.

Anderson, C. D. (2014). Social Consequences of Economic Restructuring in the Textile Industry: Change in a Southern Mill Village. Routledge. ISBN 0-8153-3622-5.

Atwah, A. A. (2012). Benefit from Potential of Fabric Design Waste and Execution of Creative Fashion, Master Thesis 2012:17.

Guilford, J. P. (1897). Intelligence, Creativity And Their Educational Implication. San Diego: Calif. RR Knaph.

Hamid, S., Skinder, B. M., \& Bhat, M. A. (2020). Zero Waste: A Sustainable Approach for Waste Management. In Innovative Waste Management Technologies for Sustainable Development (pp. 134-155). IGI Global.

Ibrahim \& Mustafa, S. A. (1996) The Plastic Potential Of Residues Textile And Its Use In The Production Of Textile Works: Master Thesis, Faculty of Art Education, Helwan University.

Jahaf, A. R. Y. (2009), "Yemeni Clothes and Ornaments", Spatial Study, Sana'a University, Yemen.

Jahaf, A. R. Y. (2013), Report about fabric remnants and environment-Environmental Protection Society-Yemen.

Modi, D. (2015). Upcycling fabric waste in Design Studio.

Rissanen, T. I. (2013). Zero-waste fashion design: a study at the intersection of cloth, fashion design and pattern cutting (Doctoral dissertation), 22:169.

Rathinamoorthy, R. (2018). Sustainable apparel production from recycled fabric waste. In Sustainable Innovations in Recycled Textiles (pp. 19-52). Springer, Singapore.

Rudofsky, B. (1947). Are Clothes Modern? An Essay on Contemporary Apparel. Chicago Paul Theobald. 
Sabbagh (2011): Fashion Design using Applique Art Techniques, PhD Thesis, Faculty of Arts and Interior Design, Umm Al Qura University, Makkah.

Sikarskie, A. (2020). Digital Research Methods in Fashion and Textile Studies. Bloomsbury Publishing.

Sabbagh (2007): Fashion Design using Applique Art Techniques, Master Thesis, Faculty of Arts and Interior Design, Umm Al Qura University, Makkah.

The Global Recycling Magazine (2016), Waste Report in the Gulf States.

\section{Websites:}

http://nationalclothing.org/41-nationalclothing/middle-east/yemen/58-yemeni-traditionaldress-yemen-is-a-country-with-a-remarkably-diverse-fashion.html

http://www.yementimes.com/en/1566/culture/755/Traditional-Sana\%E2\%80\%99ani-dressstill-in-fashion.htm

Http://aden-univ.net/NDetails.aspx?contid=197.

www.folkculturebh.org/ar/index.php?issue=18\&page=showarticle \&id=333.

https://www.yemeress.com/algomhoriah/2090246 